\title{
Current state of the roles of alcohol septal ablation and surgical myectomy in the treatment of hypertrophic obstructive cardiomyopathy
}

\author{
John S. Douglas Jr \\ Division of Cardiology, Emory University School of Medicine, Emory University Hospital, Atlanta, Georgia, USA \\ Correspondence to: John S. Douglas Jr, MD. Emory University Hospital, Suite F-606, 1364 Clifton Road, NE, Atlanta, Georgia 30322, USA. \\ Email: jdoug01@emory.edu.
}

\begin{abstract}
Hypertrophic cardiomyopathy is a genetically determined disorder resulting in left ventricular hypertrophy. In a majority of the estimated 20 million people affected worldwide, left ventricular outflow obstruction is present at rest or with provocation. The presence and degree of obstruction influence the symptomatic presentation, treatment strategies and prognosis of affected individuals. Pharmacologic therapy with beta-adrenergic blocking drugs and calcium channel blockers is the principal treatment strategy in symptomatic patients with left ventricular outflow obstruction but is ineffective in many patients. When symptoms of exertional shortness of breath, chest pain and/or syncope prove refractory to medical therapy and there is persisting left ventricular outflow obstruction, or when there is drug intolerance, septal reduction strategies (surgical myectomy and alcohol septal ablation) are quite effective. Selection of the optimal septal reduction strategy for a given patient has become controversial and is determined largely by the medical system providing treatment strategies for the patient. Regretably, there are no randomized trials comparing myectomy and ablation and none are anticipated. The comprehensive Hypertrophic Cardiomyopathy Guideline Statements published in 2011 and 2014 differ significantly with the earlier statement favoring surgical myectomy and the more recent statement giving equal class I status to the two septal reduction strategies in adult patients with drug-refractory symptoms. Recently published studies of long-term followup of patients after alcohol septal ablation in Europe, where surgical myectomy is rarely performed, confirm long-term safety and effectiveness with survival free of cardiac events exceeding $96 \%$ at 15 years. The lesser degree of discomfort and more rapid recovery associated with the minimally invasive catheter-based alcohol ablation procedure coupled with the recently published long-term safety data favor an increased use of this strategy in symptomatic adult patients with hypertrophic obstructive cardiomyopathy (HOCM).
\end{abstract}

Keywords: Hypertrophic cardiomyopathy (HCM); myectomy; alcohol septal ablation

Submitted May 08, 2019. Accepted for publication Jul 09, 2019.

doi: $10.21037 / \mathrm{cdt} .2019 .07 .02$

View this article at: http://dx.doi.org/10.21037/cdt.2019.07.02

\section{Introduction}

Hypertrophic cardiomyopathy (HCM), the most common inherited heart disease, is characterized by the presence of left ventricular hypertrophy without loading conditions or other known causes of hypertrophy. HCM, which is inherited in an autosomal dominant Mendelian pattern, is caused by one of over 2,000 mutations of genes encoding sarcomeric proteins. Based on echocardiographic surveillance, HCM has been estimated to occur in one per 500 individuals in the general population worldwide but a higher prevalence of 1 case per 200 individuals is estimated when all gene positive persons are included (1). Because of the diverse genetic makeup of affected individuals and occurrence of spontaneous mutations, genetic testing is primarily reserved for assessment of gene positivity in family members of probans. Phenotypic expressions of a 
Table 1 Management goals in HOCM

Sudden death prevention
Changes in lifestyle
Implantable cardioverter-defibrillator in high risk patients
Relief from symptoms
Changes in lifestyle
Pharmacologic therapy
Septal reduction
Surgical myectomy
Alcohol septal ablation

HOCM, hypertrophic obstructive cardiomyopathy.

given genotype are not predictable. Therefore, clinical manifestations and prognosis of gene (+) family members may vary substantiality. It has been estimated that the vast majority of genotype (+)-phenotype $(+)$ persons are asymptomatic or mildly symptomatic and have not been diagnosed with HCM. Dyspnea on exertion is the most common clinical presentation but sudden cardiac death as the first manifestation has been observed. HCM is the most common cause of sudden cardiac death in athletes and preparticipation screening is largely aimed at detecting HCM in young athletes (2). The presence of HCM disqualifies young athletes from participation in intense competitive sports in most environments. Heart failure characterized by the presence of exertional dyspnea and fatigue is the most common clinical complication in adult patients with HCM. In contrast to the patient with conventional congestive heart failure who has impaired ventricular emptying, reduced ejection fraction, volume overload, and peripheral edema, the vast majority of patients with HCM have preserved systolic ventricular function and rarely require acute hospitalization for diuresis. The availability of effective treatments in the HCM patient with heart failure account for the 20 -fold lower mortality rate compared to the conventional heart failure patient $(0.5 \%$ vs. $10 \%$ annual mortality) (3). Recognizing the presence of HCM may be difficult due to compensating life style changes to avoid symptoms and non-specific physical findings and electrocardiograms. Left ventricular outflow tract (LVOT) obstruction (LVOT pressure gradient $\geq 30 \mathrm{mmHg}$ ) at rest is present in one-third of individuals with HCM and in an additional one-third LVOT obstruction can be provoked by maneuvers that diminish left ventricular filling and volume (Valsalva maneuver, nitroglycerin, standing) or increase contractility (post-extra-systolic potentiation or exercise). The British pathologist Donald Teare's landmark description of asymmetric septal hypertrophy ushered in the beginning of our current understanding of this disorder (4). Systematic characterization of the hypertrophic obstructive cardiomyopathy (HOCM) phenotype was first performed by Braunwald et al. (5) over 50 years ago using the newly developed technique of cardiac catheterization. Since that time echocardiographic imaging has been a powerful tool to further understanding of the pathophysiology, variable phenotypes and prognosis of HCM and to monitor therapy. Magnetic resonance imaging (MRI) provides a more detailed morphologic evaluation as well as improved risk stratification by identification of late gadolinium enhancement, a measure of myocardial fibrosis. Dynamic LVOT obstruction results from a combination of factors including narrowing of the LVOT due to septal hypertrophy, abnormal anterior location of the mitral valve apparatus and resultant turbulent flow in systole that drags the longer than normal mitral valve leaflets into the LVOT. The systolic anterior motion (SAM) of the anterior mitral valve leaflet results in SAM-septal contact, mechanical impedance to left ventricular outflow and a posteriorly directed jet of mitral regurgitation. There is a positive correlation between the amount of LVOT obstruction and the severity of mitral regurgitation. In symptomatic patients without a resting LVOT pressure gradient, provocation with Valsalva maneuver, nitroglycerin, or exercise echocardiography should be performed to determine the presence of inducible LVOT obstruction. The presence of LVOT obstruction adversely affects long term outcomes with respect to mortality and is a determinant of treatment strategies.

\section{Treatment of HOCM}

The primary goals in the treatment of HOCM are prevention of sudden cardiac death (Table 1) and relief of symptoms. Strategies for sudden death prevention include life style changes and implantation of cardioverterdefibrillator devices in high risk patients (6-10). In symptomatic patients with HOCM, pharmacologic therapy is the centerpiece of treatment and is aimed at reducing LVOT obstruction, and the attendant mitral regurgitation, elevated left atrial pressure and development of pulmonary hypertension. There is no clear role for pharmacologic therapy in asymptomatic patients and, although drug 
therapy aimed at reducing LVOT obstruction can result in symptom relief, there is no evidence that it fundamentally modifies the natural history of HOCM. Tailoring medical therapy in patients with HOCM should include avoidance of medications known to increase dynamic LVOT obstruction such as vasodilators, diuretics and digitalis. Beta-adrenergic blocking agents are the mainstay of drug therapy in HOCM. They reduce LVOT obstruction by negative inotropic properties, prolong diastole and improve left ventricular filling by negative chronotropic affects and blunt the adrenergically mediated tachycardia associated with exercise $(6,10)$. Calcium-channel blockers (verapamil and diltiazem) may be added to or replace beta-blockers. Calcium-channel blockers should be used with caution in patients with severe LVOT obstruction, high pulmonary wedge pressure and/or low systemic blood pressure because of rare worsening of obstruction due to vasodilation. Disopyramide which has negative inotropic properties may be administered alone or with other agents but has significant proarrhythmic and anticholinergic side effects. It is remarkable that a clinical role for newer pharmacologic agents in the treatment of HOCM has not been established in over three decades.

In patients with HOCM whose symptoms and LVOT obstruction prove refractory to optimal medical therapy, more invasive options including dual-chamber pacing and septal reduction have been evaluated. Although, dual-chamber pacing appeared promising in initial use, randomized controlled cross-over trials uncovered a significant placebo effect with improvements in symptoms in a minority of patients. Currently, septal reduction therapy is the treatment of choice in drug-refractory HOCM. Pacing is reserved for drug-refractory patients who are poor candidates for septal reduction $(6,10,11)$.

Surgical septal myectomy, the resection of muscle from the basal septum, was pioneered by Morrow and has proved safe and effective (12) with immediate- and long-term relief of LVOT obstruction and secondary mitral regurgitation. More extensive myectomy as well as surgical approaches to mitral valve and papillary muscle abnormalities have been advocated and have inhanced the benefit of surgical treatment in more complex patients with HOCM (13-16). By eliminating LVOT obstruction, significantly reducing or abolishing mitral regurgitation, and normalizing left ventricular and left atrial pressure, surgical myectomy relieves heart failure symptoms in a high percentage of patients. In patients with concomitant problems such as atrial fibrillation, obstructive coronary or valvular heart disease, surgical solutions to these problems can be undertaken. The risk of in-hospital mortality in centers of excellence has decreased significantly to $<1 \%$ for isolated myectomy procedures $(17,18)$. However, reports from the US Nationwide Inpatient Database $(19,20)$ have revealed that most centers which performed surgical myectomy had very small numbers of procedures (median 1.0 per year) and that low volume was associated with higher mortality, longer length of stay and higher costs. There was an approximate 4-fold increase in mortality comparing the high- to low-volume tertile but the best mortality results reported by the high-volume tertile were almost 10 -fold higher than those of North American HCM centers of excellence. This information strongly supports having a few highly focused specialized HCM centers (21). A recent report from the relatively new Tufts HCM Center of 507 surgical myectomies (mean age $54 \pm 14$ years) with $0.8 \%$ 30 -day mortality, long-term survival of $94 \%$ at 5 years and $91 \%$ at 10 years equaling the age-and gender-matched general US population supports this thesis (22). In 19 patients $(3.8 \%)$ in the Tufts experience there was failure to respond symptomatically. Massive hypertrophy (septal thickness $\geq 3.0 \mathrm{~cm}$ ) was 5 -fold more common in nonresponders (23). Surgical septal myectomy is an invasive procedure requiring sternotomy and cardiopulmonary bypass and the possibility of a second cardiopulmonary bypass run if needed to correct echocardiographically determined residual mitral regurgitation or LVOT obstruction. The requirement for superb surgical skills available in only in a few centers has resulted in reduced utilization particularly in Europe where alcohol ablation became the dominant septal reduction strategy (24). There are a few strong international myectomy programs in Italy, Israel, Belgium, the Netherlands and China but a need for more septal myectomy surgeons and more septal myectomy centers in Europe has been expressed (24-26). The most recent $\mathrm{HCM}$ guideline statement recommends 10 myectomies per operator/year as reasonable experience (10), a goal that can be met by a comparatively few centers particularly in Europe.

Alcohol septal ablation is a minimally invasive catheterbased technique for achieving septal reduction first reported by Sigwart in 1995 (27). Using angiographic and echocardiographic imaging during contrast media injections into septal perforating arteries, the arterial supply of the SAM-septal contact area of the basal septum is identified. Injection of a small amount of alcohol through an inflated balloon catheter leads to an iatrogenic myocardial infarction, 

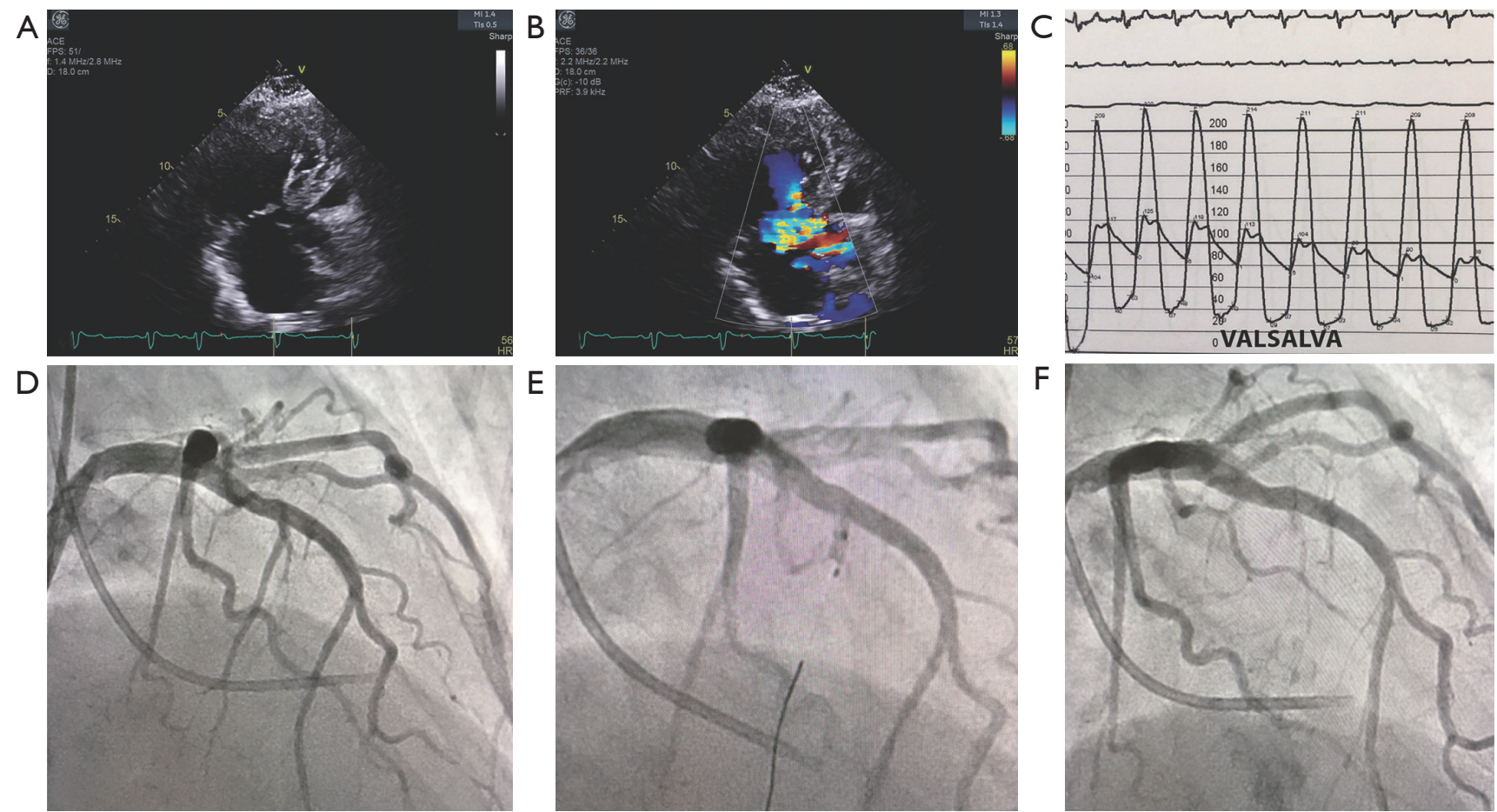

E

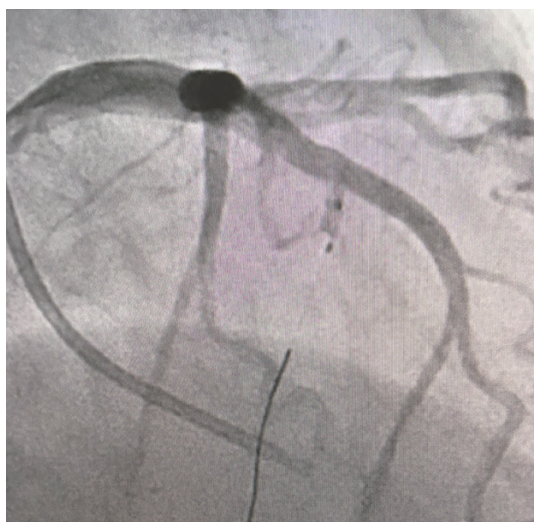

F
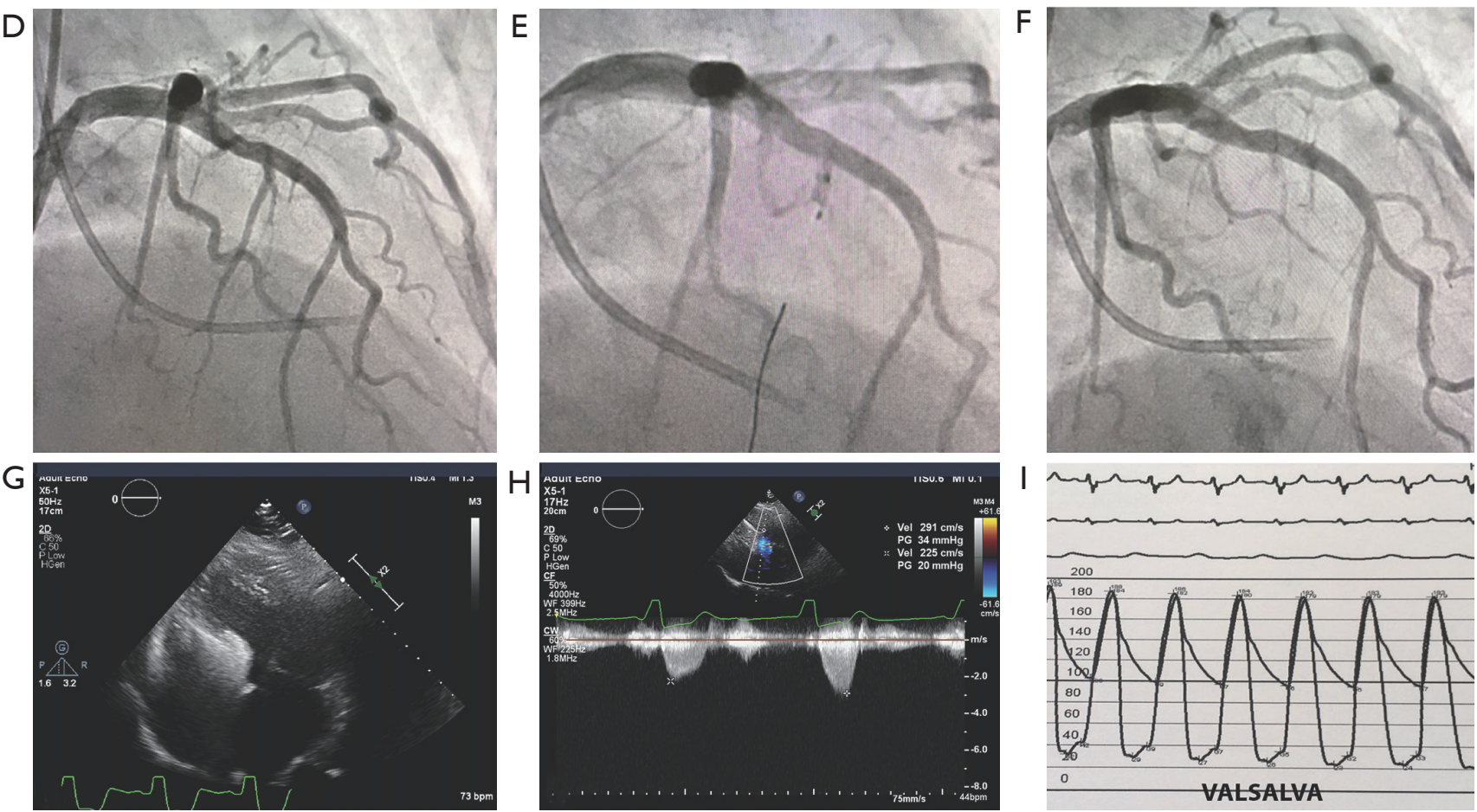

Figure 1 A 65 -year-old female had disabling symptoms of shortness of breath and fatigue attributed to HOCM in spite of maximal tolerated medical therapy. Echocardiogram revealed basal septal thickness of $2.2 \mathrm{~cm}$, a narrow LVOT, SAM-septal contact in systole (A) and LVOT turbulence (B). Invasive evaluation revealed an $80-90 \mathrm{mmHg}$ resting LVOT pressure gradient which increased to $120 \mathrm{mmHg}$ with initiation of a Valsalva maneuver with decrease in systolic blood pressure to $85 \mathrm{mmHg}$ and decrease in pulse pressure (C). A large septal branch was evident (D). This septal artery was entered with a $2.5 \times 6 \mathrm{~mm}$ over the wire balloon catheter which was occlusive (E). Injection of agitated contrast media through the inflated balloon catheter caused brightening of the left side of the basal septum on echocardiography without brightening of other cardiac structures. Following injection of $2 \mathrm{cc}$ of alcohol the septal artery was occluded (F). Increased brightening following alcohol injection was confined to the left side of the basal septum and SAM disappeared (G). A small inducible LVOT gradient appeared to be present by echocardiography $(\mathrm{H})$, but catheter measurement revealed no LVOT pressure gradient at rest, with Valsalva maneuver (I), or following of administration of 100 micrograms of nitroglycerin intravenously. Troponin- $\mathrm{I}$ was $34 \mathrm{ng} / \mathrm{mL}$ the following morning. The patient subsequently returned to an active lifestyle with no exercise limitation and no symptoms. This favorable hemodynamic and symptomatic response is common in patients with HOCM, basal septal hypertrophy and LVOT obstruction due to SAM-septal contact.

paradoxical septal motion, immediate abolishment of SAM, and reduction of LVOT obstruction (see Figure 1) with further decreases as septal thinning occurs. Longterm benefits include reductions in mitral regurgitation and in left ventricular end-diastolic pressure, reduced left atrial pressure and size, regression of LV hypertrophy and relief of pulmonary hypertension (28-32). Septal ablation leads to improvement in heart failure symptoms 
and exercise capacity measurable by higher peak oxygen consumption. As with surgical myectomy, patients after septal ablation have been shown to have long-term survival similar to age and sex matched members of the general population (29). Alcohol septal ablation has the advantage of being less invasive than surgical myectomy, requires less hospitalization and has a shorter recovery period. The less invasive procedure with earlier return to active life style has resulted in an increase in use of alcohol septal ablation worldwide and a reduction in surgical myectomy (24-26). The primary limitation of septal ablation is the effect on the conduction system. Right bundle branch block occurs in about $60 \%$ of patients making need for permanent pacing very high in patients with left bundle branch block. In patients with normal baseline electrocardiogram, rates for permanent pacing as high as $20 \%$ have been reported (29). Among 31 consecutive patients undergoing alcohol septal ablation, Reinhard and colleagues (33) reported that $55 \%$ of patients experienced atrioventricular (AV) block during the procedure, with persisting $\mathrm{AV}$ block in $23 \%$ at 14 hours, $18 \%$ at 3 days, $7 \%$ at 1 week and only one patient (3\%) required a permanent pacemaker. These investigators recommended waiting for $\geq 7$ days of persistent AV block before pacemaker implantation. In contrast surgical myectomy results in left bundle branch block in about $50 \%$ of patients.

\section{Comparison of myectomy and septal ablation}

The older myectomy procedure, first performed in 1958, has been shown to be safe and to convey excellent long-term symptom relief and survival when performed by experienced operators in centers of excellence. Unlike minimally invasive percutaneous coronary angioplasty and trans-catheter aortic valve replacement procedures which were compared to surgery in randomized trials, no randomized trial of ablation and myectomy has been performed and none is expected. Until recently, the comparatively short follow-up and small sample size of ablation-treated patients and the specter of an alcohol induced septal scar in an arrhythmogenic milieu led to concerns regarding increased risk of sudden cardiac death following septal ablation. This is reflected in the 2011 ACCF/AHA Guideline statement (6) where myectomy is the preferred septal reduction strategy (class IIa) with ablation recommended when surgery is contraindicated or high risk (class IIa) or ablation is considered as an alternative to myectomy in a well-informed patient (class IIb). The 2011 Guideline further stated that alcohol ablation should not be done in patients less than 21 years of age (class III) and discouraged in those younger than 40 or with septal thickness $\geq 30 \mathrm{~mm}$. There were some reports of adverse outcomes (19,20,33-35). The US Nationwide Inpatient Database 2003-2011 surveying over 1,000 hospitals reported that the median number of alcohol ablations was 0.7 per year per institution with slowly increasing rates of ASA. There was a lower incidence of death and acute renal failure in the higher-volume centers (20). The EURO-ASA registry which evaluated acute and longterm data of 1,000 patients treated with alcohol ablation in 10 tertiary centers from 7 European countries confirmed the safety, and durable relief of LVOT obstruction and symptoms in patients with HOCM (36) including younger patients $\leq 50$ years of age $(37,38)$, those with mild class II symptoms (39), and mild septal hypertrophy $\leq 16 \mathrm{~mm}$ (40) and reported that institution experience (41) and the degree of relief of LVOT obstruction (42) are important determinants of long-term outcome. These favorable results confirm and extend the earlier observational studies $(28,29)$ and multicenter registries (43-45) of patients treated with alcohol ablation.

Among 177 patients at the Mayo Clinic treated with alcohol ablation and compared to myectomy-treated patients, 8 -year survival was $79 \%$, comparable to surgically treated patients and to the expected survival for matched US general population (29). In a more recent study using 2:1 propensity matching, 344 patients who underwent myectomy were compared to 167 matched patients who underwent septal ablation (46). There were no significant differences in procedural complications, survival or functional status achieved but more ablation patients required permanent pacemaker insertion $(17.4 \%$ vs. $3.9 \%, \mathrm{P}<0.001)$ and reintervention. Several meta-analyses have been reported comparing ablation and myectomy (47-49). The largest (50) and most recent included twentytwo ablation cohorts $(\mathrm{N}=4,213$; follow-up $=6.6$ years $)$ and 23 myectomy cohorts $(\mathrm{N}=4,240$; follow-up $=6.8$ years $)$. Ablation-treated patients were almost a decade older (54 vs. $45, \mathrm{P}<0.001$ ). Septal myectomy was associated with higher periprocedural mortality and stroke rate and ablation treated patients had more need for permanent pacing $(10 \%$ vs. $5 \%, \mathrm{P}<0.001)$ and repeat septal reduction $(11 \%$ vs. $1.5 \%, \mathrm{P}<0.001)$. There was no difference with regard to long-term all-cause mortality, cardiovascular mortality or sudden cardiac death. Leonardi and colleagues reported that despite greater septal thickness younger patients $(<45$ years of age) obtained equally good relief of LVOT obstruction 
and symptom relief with fewer complications (51). In a large single center study of 952 patients who underwent ablation and were followed $6.0 \pm 5$ years, the mean age was $55.7 \pm 15$ years (range, 14.9 to 85.1 years). In-hospital mortality occurred in two patients (0.2\%) (52). A total of $94 \%$ reported improved symptoms and the estimated survival free of cardiac events at 15 years was $96.5 \%$. There were only 4 sudden cardiac deaths among 952 patients during the 6-year follow-up. In a European registry, 26 patients who underwent alcohol ablation had septal thickness $\geq 30 \mathrm{~mm}$ (median, $32 \mathrm{~mm}$ ) with equal efficiency compared to patients without massive septal hypertrophy. These studies suggest that alcohol septal ablation and myectomy result in similar relief of symptoms and long-term survival in adult patients and that septal ablation may be effective in selected patients with massive hypertrophy. Registries, meta-analyses and the excellent long-term outcomes recently reported in a single center observation (52) provide reassurance that alcohol septal ablation does not increase the risk of late sudden cardiac death. These findings support the 2014 European Guideline Statement granting equipoise between the selection of septal ablation or myectomy in the adult patient with drugrefractory HOCM (10).

\section{Performance of alcobol septal ablation in 2019}

The goal in the performance of septal ablation is to use echocardiogram guidance to identify the septal artery that supplies the portion of the basal septum that contacts the anterior mitral leaflet during systole and to deliver alcohol (approximately $1 \mathrm{cc}$ per $1 \mathrm{~cm}$ septal thickness). In the largest single center experience reported, a target septal branch could not be identified in 62 of 1,014 (6.1\%) patients and the procedure was aborted without alcohol injection (52). These operators confined the procedure to injection of a single septal branch, a strategy that resulted in a $39.6 \%$ rate of complete heart block during the procedure, a $10.5 \%$ permanent pacemaker insertion rate, a reduction in LVOT pressure gradient from 64 to $34 \mathrm{mmHg}(\mathrm{P}<0.001)$, and a need for repeat ablation in $17 \%$ of patients. This procedural strategy resulted in an excellent 15-year survival free of cardiac events. Many operators attempt to achieve a LVOT pressure gradient $\leq 20 \mathrm{mmHg}$, a strategy that frequently requires injection of alcohol in more than one septal branch.

The use of cardiac magnetic resonance (CMR) imaging to study the results of myectomy and alcohol ablation has provided important insights into the different effects of these two techniques (53). CMR showed that myectomy removed muscle tissue ( $6 \pm 4$ grams by weight) from the $L V$ aspect of the basal anterior septum whereas the muscle necrosis induced by alcohol was substantially larger ( $16 \pm 7$ grams) affecting different locations causing transmural inferior septal necrosis in $75 \%$ of patients. In $25 \%$ of patients necrosis was confined to the right side of the septum sparing the anterior basal septum with resulting significant residual LVOT obstruction on follow-up. This variability in treatment affect with alcohol ablation is a significant limitation. In treatment of 350 patients with alcohol septal ablation, the author has attempted to avoid this limitation by preferentially selecting septal branches arising from diagonal and ramus intermedius coronary arteries. Septal branches arising from diagonal or ramus intermedius arteries are more likely to supply the left side of the septum, the ablation target

\section{Conclusions}

In selected patients with drug-refractory symptoms attributed to HOCM, alcohol septal ablation is a safe and effective treatment strategy. Procedure related mortality is equal or less than with surgical myectomy, morbidity is substantially reduced and long-term symptom relief and survival are similar. Permanent pacing and second ablation procedures are required in a significant minority of patients. A continued growth in the use of this septal reduction technique in high volume HOCM centers of excellence is expected.

\section{Acknowledgments}

None.

\section{Footnote}

Conflicts of Interest: The author has no conflicts of interest to declare.

Ethical Statement: The author is accountable for all aspects of the work in ensuring that questions related to the accuracy or integrity of any part of the work are appropriately investigated and resolved.

\section{References}

1. Semsarian C, Ingles J, Maron MS, et al. New perspectives on the prevalence of hypertrophic cardiomyopathy. J Am 
Coll Cardiol 2015;65:1249-54.

2. Maron BJ. Clinical course and management of hypertrophic cardiomyopathy. N Engl J Med 2018;379:655-68.

3. Maron BJ, Rowin E, Udelson JE, et al. Clinical spectrum and management of heart failure in hypertrophic cardiomyopathy. JACC Heart Fail 2018;6:353-63.

4. Teare D. Asymmetrical hypertrophy of the heart in young adults. Br Heart J 1958;20:1-8.

5. Braunwald E, Lambrew CT, Rockoff SD, et al. Idiopathic hypertrophic subaortic stenosis. A description of the disease based upon an analysis of 64 patients. Circulation 1964;30:4-119.

6. Gersh B, Maron BJ, Bonow RO, et al. 2011 ACCF/AHA guideline for the diagnosis and treatment of hypertrophic cardiomyopathy: a report of the American College of Cardiology Foundation/American Heart Association Task Force on Practice Guidelines. J Am Coll Cardiol 2011;58:2703-38.

7. O'Mahony C, Jichi F, Pavlou M, et al. Hypertrophic Cardiomyopathy Outcomes Investigators. A novel clinical risk prediction model for sudden cardiac death in hypertrophic cardiomyopathy (HCM Risk-SCD). Eur Heart J 2014;35:2010-20.

8. Maron BJ, Rowin EJ, Casey SA, et al. Hypertrophic cardiomyopathy in adulthood associated with low cardiovascular mortality with contemporary management strategies. J Am Coll Cardiol 2015;65:1915-28.

9. Maron BJ, Casey SA, Chan RH, et al. Independent assessment of the European Society of Cardiology Sudden Death Risk model for hypertrophic cardiomyopathy. Am J Cardiol 2015;116:757-64.

10. Elliott PM, Anastasakis A, Borger MA, et al. 2014 European Society of Cardiology guidelines on diagnosis and management of hypertrophic cardiomyopathy. Eur Heart J 2014;35:2733-79.

11. Feldman DN, Douglas JS Jr, Naidu SS. Indications for and individualization of Septal Reduction Therapy. In: Naidu SS. editor. Hypertrophic Cardiomyopathy. London: Springer-Verlag, 2015:207-22.

12. Morrow AG, Reitz BA, Epstein SE, et al. Operative treatment in hypertrophic subaortic stenosis. Techniques and the results of pre and postoperative assessments in 83 patients. Circulation 1975;52:88-102.

13. Klues HG, Maron BJ, Dollar AL, et al. Diversity of structural mitral valve alterations in hypertrophic cardiomyopathy. Circulation 1992;85:1651-60.

14. Klues HG, Roberts WC, Maron BJ. Morphological determinants of echocardiographic patterns of mitral valve systolic anterior motion in obstructive hypertrophic cardiomyopathy. Circulation 1993;87:1570-9.

15. Messemer BJ. Extended myectomy for hypertrophic obstructive cardiomyopathy. Ann Thorac Surg 1994;58:575-7.

16. Kwon DH, Smedira NG, Thamilarasan M, et al. Characteristics and surgical outcomes of symptomatic patients with hypertrophic cardiomyopathy with abnormal papillary muscle morphology undergoing papillary muscle reorientation. J Thorac Cardiovasc Surg 2010;140:317-24.

17. Kotkar KD, Said SM, Dearani JA, et al. Hypertrophic obstructive cardiomyopathy: the Mayo Clinic experience. Ann Cardiothorac Surg 2017;6:329-36.

18. Hodges K, Rivas CG, Anguilera J, et al. Surgical management of left ventricular outflow tract obstruction in a specialized hypertrophic obstructive cardiomyopathy center. J Thorac Cardiovasc Surg 2019;157:2289-99.

19. Panaich SS, Badheka AO, Chothani A, et al. Results of ventricular septal myectomy and hypertrophic cardiomyopathy (from Nationwife Inpatient Sample [1998-2010]). Am J Cardiol 2014;114:1390-5.

20. Kim LK, Swaminathan RV, Looser P, et al. Hospital volume outcomes after septal myectomy and alcohol septal ablation for treatment of obstructive hypertrophic cardiomyopathy: US Nationwide Inpatient Database. 2003-2011. JAMA Cardiol 2016;1:324-32.

21. Ommen SR, Nishimura RA. Hypertrophic cardiomyopathy-one case per year? A clarion call to do what is right. JAMA Cardiol 2016;1:333-4.

22. Rastegar H, Boll G, Rowin EJ, et al. Results of surgical septal myectomy for obstructive hypertrophic cardiomyopathy: the Tufts experience. Ann Cardiothorac Surg 2017;6:353-63.

23. Wells S, Rowin EJ, Boll G, et al. Clinical profile of nonresponse to surgical myectomy with obstructive hypertrophic cardiomyopathy. Am J Med 2018;131:e235-9.

24. Maron BJ, Yacoub M, Derani JA. Benefits of surgery for obstructive hypertrophic cardiomyopathy: bring septal myectomy back for European patients. Eur Heart J 2011;32:1055-8.

25. Spirito P, Ferrozzi P. We need more high volume myectomy centers in Europe. Eur J Heart Fail 2018;20:406-8.

26. Maron BJ, Dearani JA, Maron MS, et al. Why we need more septal myectomy surgeons: an emerging recognition. J Thorac Cardiovasc Surg 2017;154:1681-5. 
27. Sigwart U. Non-surgical myocardial reduction for hypertrophic obstructive cardiomyopathy. Lancet 1995;346:211-4.

28. Sorajja P, Valeti U, Nishimura RA, et al. Outcome of alcohol septal ablation for obstructive hypertrophic cardiomyopathy. Circulation 2008;118:131-9.

29. Sorajja P, Ommen SR, Holmes DR Jr, et al. Survival after alcohol septal ablation for obstructive hypertrophic cardiomyopathy. Circulation 2012;126:2374-80.

30. Nagueh SF, Lakkis NM, Middleton KJ, et al. Changes in left ventricular filling and left atrial function six months after nonsurgical septal reduction therapy for hypertrophic obstructive cardiomyopathy. J Am Coll Cardiol 1999;34:1123-8

31. Sitges M, Shiota T, Lever HM, et al. Comparison of left ventricular diastolic function in obstructive hypertrophic cardiomyopathy patients undergoing percutaneous septal alcohol ablation versus surgical myotomy/myectomy. Am J Cardiol 2003;91:817-21.

32. Mazur W, Nagueh SF, Lakkis NM, et al. Regression of left ventricular hypertrophy after nonsurgical septal reduction therapy for hypertrophic obstructive cardiomyopathy. Circulation 2001;103:1492-6.

33. Reinhard W, Ten Cate FJ, Scholten M, et al. Permanent pacing for complete atrioventricular block After nonsurgical (Alcohol) septal reduction in patients with obstructive hypertrophic cardiomyopathy. Am J Cardiol 2004;93:1064-6.

34. Noseworthy PA, Rosenberg MA, Fifer MA, et al. Ventricular arrhythmia following alcohol septal ablation for obstructive hypertrophic cardiomyopathy. Am J Cardiol 2009;104:128-32.

35. ten Cate FJ, Soliman OL, Michels M, et al. Longterm outcome of alcohol septal ablation in patients with obstructive hypertrophic cardiomyopathy: a word of caution. Circ Heart Fail 2010;3:362-9.

36. Veselka J, Jensen MK, Liebregts M, et al. Long term clinical outcome after alcohol septal ablation for obstructive hypertrophic cardiomyopathy: results from the Euro-ASA registry. Eur Heart J 2016;37:1517-23.

37. Liebregts M, Faber L, Jenses MK, et al. Outcomes of alcohol septal ablation in younger patients with obstructive hypertrophic cardiomyopathy. JACC Cardiovasc Interv 2017;10:1134-43.

38. Veselka J, Krejci J, Tomasov P, et al. Survival of patients $\leq 50$ years of age after alcohol septal ablation for hypertrophic obstructive cardiomyopathy. Can J Cardiol 2014;30:634-8.
39. Veselka J, Faber L, Liebregts M, et al. Outcome of alcohol septal ablation in mildly symptomatic patients with hypertrophic obstructive cardiomyopathy: a long-term follow-up study based on the Euro-ASA registry. J Am Heart Assoc 2017;6:e005735.

40. Veselka J, Faber L, Liebregts M, et al. Short- and longterm outcomes of alcohol septal ablation for hypertrophic obstructive cardiomyopathy in patients with mild left ventricular hypertrophy: a propensity score matching analysis. Eur Heart J 2019;40:1681-7.

41. Veselka J, Faber L, Jensen MK, et al. Effect of institutional experience on outcomes of alcohol septal ablation for hypertrophic obstructive cardiomyopathy. Can J Cardiol 2018;34:16-22.

42. Veselka J, Tomasov P, Januska J, et al. Obstruction after alcohol septal ablation is associated with cardiovascular mortality events. Heart 2016;102:1793-6.

43. Nagueh SF, Groves BM, Schwartz L, et al. Alcohol septal ablation for the treatment of hypertrophic obstructive cardiomyopathy. A multicenter North American registry. J Am Coll Cardiol 2011;58:2322-8.

44. Fernandes VL, Nielsen C, Nagueh SF, et al. Follow-up of alcohol septal ablation for symptomatic hypertrophic obstructive cardiomyopathy: The Baylor and Medical University of South Carolina experience 1996 to 2007. JACC Cardiovasc Interv 2008;1:561-70.

45. Jensen MK, Almaas VM, Jacobsson L, et al. Long-term outcome of percutaneous transluminal septal myocardial ablation in hypertrophic obstructive cardiomyopathy. A Scandinavian multicenter study. Circ Cardiovasc Interv 2011;4:256-65.

46. Nguyen A, Schaff HV, Hang D, et al. Surgical myectomy versus alcohol septal ablation for obstructive hypertrophic cardiomyopathy: a propensity score-matched cohort. J Thorac Cardiovasc Surg 2019;157:306-15.e3.

47. Agarwal S, Tuzcu EM, Desai MY, et al. Updated metaanalysis of septal alcohol ablation versus myectomy for hypertrophic cardiomyopathy. J Am Coll Cardiol 2010;55:823-34.

48. Leonardi RA, Kransdorf EP, Simel DL, et al. Metaanalyses of septal reduction therapies for obstructive hypertrophic cardiomyopathy: comparative rates of overall mortality and sudden cardiac death after treatment. Circ Cardiovasc Interv 2010;3:97.

49. Liebregts M, Vriesendorp PA, Mahmoodi BK, et al. A systematic review and meta-analysis of long-term outcomes after septal reduction therapy in patients with hypertrophic cardiomyopathy. JACC Heart Fail 2015;3:896-905. 
50. Osman M, Kheiri B, Osman K, et al. Alcohol septal ablation for symptomatic hypertrophic obstructive cardiomyopathy: systematic review and meta-analysis. Clin Cardiol 2019;42:190-7.

51. Leonardi RA, Townsend JC, Patel CA, et al. Alcohol septal ablation for obstructive hypertrophic cardiomyopathy: outcomes in young, middle-aged, and elderly patients. Catheter Cardiovasc Interv 2013;82:838-45.

Cite this article as: Douglas JS Jr. Current state of the roles of alcohol septal ablation and surgical myectomy in the treatment of hypertrophic obstructive cardiomyopathy. Cardiovasc Diagn Ther 2020;10(1):36-44. doi: 10.21037/cdt.2019.07.02
52. Batzner A, Pfeiffer B, Neugebauer A, et al. Survival after alcohol septal ablation with hypertrophic obstructive cardiomyopathy. J Am Coll Cardiol 2018;72:3087-94.

53. Valeti US, Nishimura RA, Holmes DR, et al. Comparison of surgical septal myectomy and alcohol septal ablation with cardiac magnetic resonance imaging in patients with hypertrophic obstructive cardiomyopathy. J Am Coll Cardiol 2007;49:350-7. 